\title{
Fourth and Fifth Metacarpal Base Arthrodesis for Posttraumatic Arthritis of Fifth Carpometacarpal Joint
}

\section{Chul-Hyung Kang, Eun-Sok Son, Chul-Hyun Cho \\ Department of Orthopedic Surgery, Keimyung University School of Medicine, Daegu, Korea}

Received: October 8, 2013

Revised: November 2, 2013

Accepted: November 12, 2013

Correspondence to: Chul-Hyun Cho

Department of Orthopedic Surgery,

Keimyung University School of Medicine,

56 Dalseong-ro, Jung-gu, Daegu 700-712,

Korea

TEL: +82-53-250-7729

FAX: +82-53-250-7205

E-mail: oscho5362@dsmc.or.kr

This is an Open Access article distributed under the terms of the Creative Commons Attribution Non-Commercial License (http://creativecommons.org/ licenses/bync/3.0/) which permits unrestricted noncommercial use, distribution, and reproduction in any medium, provided the original work is properly cited.
Posttraumatic arthritis of the fifth carpometacarpal joint occurs as a sequelae of intraarticular comminuted fracture or missed and untreated fracture. If it is inappropriately managed, persistent pain and functional disability of the hand can occur. Arthrodesis, resection arthroplasty, or interposition arthroplasty has been reported as the treatment for the arthritis. However, outcome studies for operative treatment of the fifth carpometacarpal arthritis have been rarely reported. We report a case of the fifth carpometacarpal arthritis occurred after missed fracture, which was successfully treated with fourth, fifth metacarpal base arthrodesis.

Keywords: Carpometacarpal joint, Fracture, Arthritis, Arthrodesis

\section{서론}

제5 수근중수 관절염은 관절 내 골절 및 탈구의 진단이 간 과되거나 지연된 경우에 잘 발생한다 1,2 . 수근중수 관절의 불일 치 상태가 지속되면 외상성 관절염으로 진행하게 되며, 이로 인해 지속적인 동통, 관절 운동 범위의 감소, 수부 기능의 저 하를 초래하게 된다. 제 5 수근중수 관절염의 치료로는 유구 중수 관절유합술 ${ }^{3}$, 절제 관절성형술 ${ }^{4}$, 실리콘 또는 건 삽입 관 절성형술 5,6 등이 있다. 유구중수 관절유합술은 횡 중수골 궁 (transverse metacarpal arch)의 정상적인 움직임이 없어지
게 되고, 제 5 중수골 기저부의 절제 관절성형술 또는 삽입 관 절성형술은 제5 수지의 단축과 함께 부정 회전(malrotation) 및 부정 정렬(malalignment)을 일으킬 수 있다는 단점이 보 고되어 있다. 또한 몇몇 저자들에 의해 기존의 관절유합술과 는 다른 제 5 수지 중수골 기저부를 절제한 다음, 제 4 중수골 기저부와의 유합을 포함하는 안정화된 관절유합술을 소개되 었다 7.8 . 그러나, 제 5 수근중수 외상성 관절염의 드문 빈도로 인해 그 치료 결과에 대한 보고가 전 세계적으로 드물며 국내 에서는 거의 보고된 바가 없다.

저자들은 24 세 남자에서 진단이 간과된 후에 발생한 제5 수 
근중수 외상성 관절염에 대해 제 4,5 중수 기저부 관절유합술 을 시행한 후 좋은 결과를 경험하였기에 문헌 고찰과 함께 보 고하고자 한다.

\section{증례}

22세 남자 환자가 좌측 수부의 동통을 주소로 내원하였다. 3 개월 전 벽에 부딪히면서 좌측 제 5 중수골 부위에 동통 및 종 창이 있었으나 특별한 치료 없이 지냈다. 수상 후 일상 생활은 가능하였으나 물건을 잡거나 손에 힘을 주어 사용할 때 동통 이 악화되며, 그 동통으로 인하여 일을 하기가 어렵다고 호소 하였다. 진찰 검사상 좌측 제 5 중수골 기저부에 현저한 압통이 있었으며 종창은 관찰되지 않았다. 건측에 비해 좌측 제 5 수지 의 굴곡 운동이 경미한 제한이 있었지만, 거의 정상에 가까운 관절 운동 범위를 보였다. 수술 전에 시행한 파악력 검사에서 우측은 $38 \mathrm{~kg}$, 좌측 $11 \mathrm{~kg}$ 였다.

단순방사선 사진 및 컴퓨터단층촬영상 좌측 제 5 중수골 기
저부 및 유구골의 관절 내 골절로 인한 외상성 관절염 소견과 함께 중수골 기저부가 유구골의 관절면에 감입(impaction)된 소견을 보였다(Fig. 1). 제5 수근중수 관절 내 골절의 진단이 간과된 후에 발생한 외상성 관절염에 대해 절제 관절성형술 및 제 4,5 중수 기저부 관절유합술을 계획하였다. 전신마취하 에 제 5 수근중수 관절 부위에 약 $3 \mathrm{~cm}$ 의 종절개를 시행하고 척골 신경의 배측 가지 및 신전건을 요측으로 견인하였다. 제5 수근중수 관절막을 절개하니 관절 내 골절로 인해 관절면이 완전히 파괴된 소견을 확인할 수 있었다. 유구골의 관절면에 감입되어 있던 제 5 중수골 기저부를 $0.5 \mathrm{~cm}$ 정도 절골술을 시 행하고 유구골의 관절면 절제술도 동시에 시행하였다. 그러나 유구골이 제 4 중수골 기저부와 이루는 관절면은 보존하였다. 이 후 제 4,5 중수골간 관절 부위에 있는 조직을 절제하고 골 이식을 할 공간을 확보하였다. 동측의 장골에서 자가 해면골 을 채취하였고 골막도 $2 \times 1 \mathrm{~cm}$ 가량 같이 채취하였다. C형 방 사선 투시 장치하에 제 5 수지의 길이를 유지하기 위해 견인 한 상태에서 $2.7 \mathrm{~mm}$ 피질 나사 2 개를 제 4,5 중수골 간부를 통
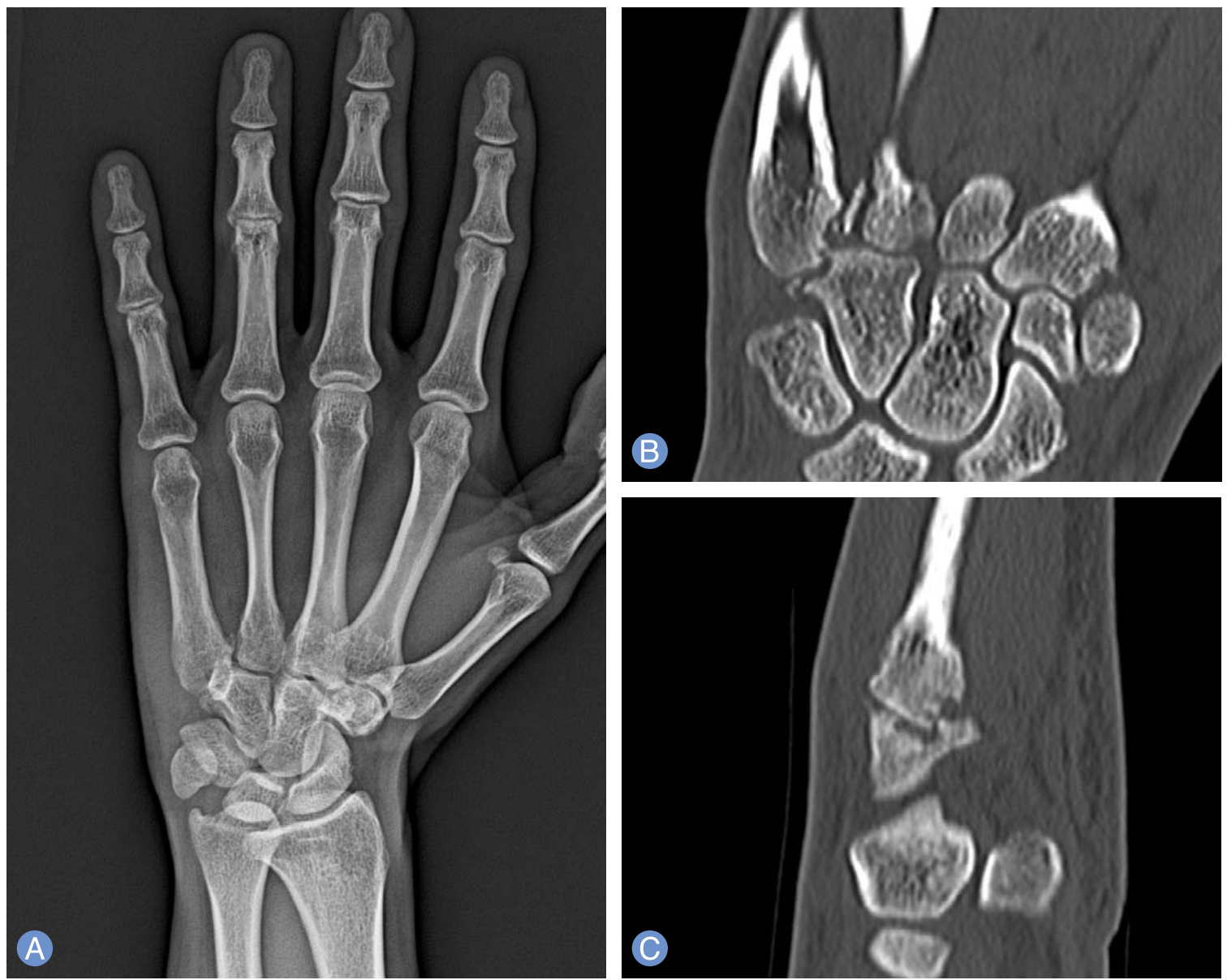

Fig. 1. Anteroposterior plain radiograph (A) and computed tomography images (B, C) show post-traumatic arthritis by a missed hamatometacarpal fracture with impaction. 

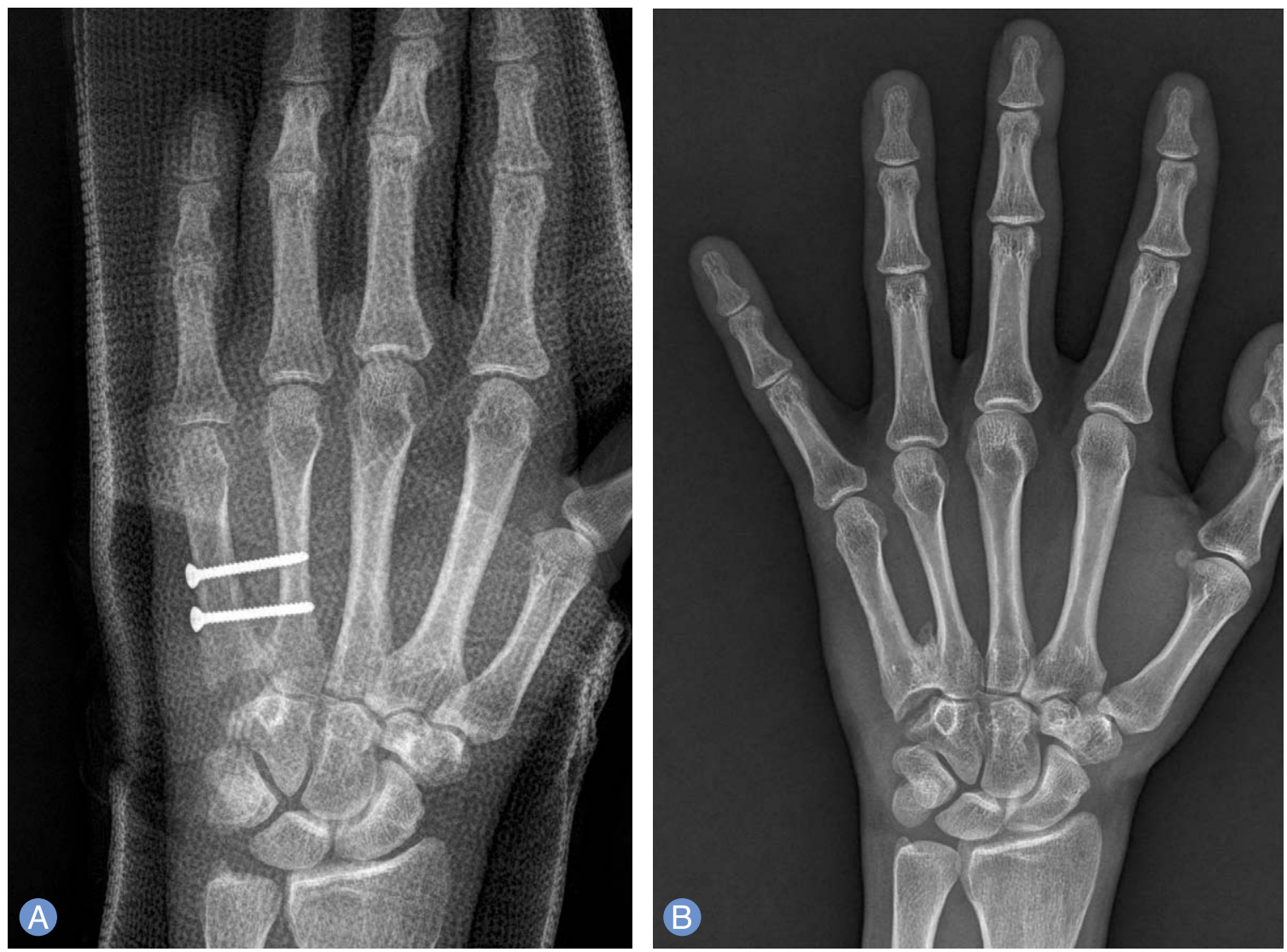

Fig. 2. Anteroposterior plain radiographs after operation (A) and at postoperative 18 months show the fourth, fifth metacarpal arthrodesis with resection arthroplasty.

해 고정하였다. 제 4,5 중수골 기저부 사이의 확보된 공간에 자가 해면골 이식을 하였으며, 유구중수 관절 절제술 시행 후 생긴 공간에 골막을 삽입하였다.

수술 후 단상지 석고 고정술 시행하였고 수술 후 4주째 석고 고정 제거한 다음 수지의 능동적 및 수동적 관절 운동을 시작 하였다. 수술 후 16 주째 유합 소견을 보여 금속 나사를 제거하 였다. 수술 후 18 개월째 촬영한 단순방사선 사진상 제 5 수지 의 단축 및 관절염의 재발 소견은 없었다(Fig. 2). 환자는 간헐 적인 동통이 있었지만 정상적인 수지 관절 운동 범위를 보였 으며, 파악력 검사상 우측 $41 \mathrm{~kg}$, 좌측 $39 \mathrm{~kg}$ 로 거의 정상에 가까운 수부 기능을 보여 직업으로 복귀가 가능하였다.

\section{고찰}

제 4,5 수지 및 중수골이 손의 기능에 중요한 부분을 차지하 는 것은 이미 알려져 있다. 제 5 수근중수 관절은 $30^{\circ}$ 의 굴곡신전 운동을 가지며 회전 운동이 가능하여 손을 펴거나 오므 린 상태 모두에서 물건을 들고 유지할 수 있도록 한다 ${ }^{2,7}$. 이런
관절의 운동은 강한 수근중수 인대 및 중수골간 인대들에 의 해 안정화 된다. 제 5 수근중수 외상성 관절염은 관절 내 심한 분쇄 골절이나 정확한 진단이 되지 않아 적절한 치료를 받지 못한 경우에 잘 발생한다 ${ }^{1,2}$. 제 5 중수골 기저부 관절 내 골절은 강력한 인대들과 척수근 신근에 의해 중수골이 전위되면서 불 안정성을 나타내게 되며, 이로 인해 관절면의 불일치, 부정 유 합 등으로 인해 관절염이 초래될 수 있다. 이렇게 발생된 외 상성 관절염은 지속적인 동통을 유발하며, 횡 중수골 궁의 유 연성을 감소시켜 물건을 잡고 유지할 수 있는 수부 기능을 저 하시킨다. 본 증례의 경우에서도 마찬가지로, 환자는 수상 당 시 단순한 타박상으로 생각하고 병원을 방문하지 않았으며 수 상 후 3 개월째 본원 방문 당시 촬영한 단순방사선 및 컴퓨터단 층촬영상 심한 관절 내 불일치 및 외상성 관절염 소견이 관찰 되었다. 수술 전 측정한 좌측 수부의 파악력은 우측의 $30 \%$ 로 현저히 감소된 소견을 보였다.

수술적 치료로는 유구중수 관절유합술 ${ }^{3}$, 절제 관절성형술4, 실리콘 또는 건 삽입 관절성형술 5,6 , 제 4,5 중수골 기저부 관절 유합술 ${ }^{8}$ 등이 소개되어 있다. 그러나 현재까지 이러한 여러 
가지 수술적 방법에 대한 치료 결과에 대한 연구는 극히 드문 실정이다. 유구중수 관절유합술은 가장 많이 이용되고 있으 며, Clendenin과 $\mathrm{Smith}^{3}$ 는 동통을 감소시키고 파악력을 향상 시킬 수 있는 효과적인 수술 방법임을 보고하였다. 그러나 유 구중수 관절 및 횡 중수골 궁의 운동을 제한하여 기능의 소실 을 가져올 수 있는 문제점이 제기되었고 또한 삼각유구 관절 의 보상 운동이 지속되어 이차적인 관절염을 야기할 수 있다 고 보고하였다. 실리콘을 이용한 관절성형술은 골절이나 탈 구의 위험성이 있고 장기적으로 실리콘 활액막염의 위험성이 제기 되었다. Gainor 등이 시행한 건을 이용한 삽입 관절성 형술에서는 중수골이 평균 $4 \mathrm{~mm}$ 정도 단축이 발생하였으며, 관절의 안정성이 소실되었기 때문에 길이, 회전, 정렬에 대한 문제가 있음을 보고하였다.

1994년 Dubert는 정상에 가까운 제5 수지의 길이, 회전, 정렬을 보존할 수 있는 제 4,5 중수골간 관절유합술이 유구중 수 관절유합술의 문제점을 해결할 수 있는 대안이 될 수 있다 고 하였다. 기존의 관절유합술과는 다른 제 5 수지 중수골 기저 부를 절제한 다음, 제 4 중수골 기저부와의 유합을 이루게 하는 술식이다. 이 후 Bain 등이 제 4,5 중수골 기저부 관절유합술 을 시행한 5 예를 보고하였으며, 5 예 모두 동통 없이 만족할 만 한 임상적 및 방사선학적 결과를 보고하였다.

본 저자들은 Bain 등이 소개한 변형 Dubert법을 이용하였 다. 제 5 중수골의 기저부를 절제하여 제 4 중수골과의 관절 고정술을 시행함과 동시에 관절염의 재발을 막기 위해 절제 한 유구중수 관절 내의 공간에 장골에서 채취한 골막을 삽입 하는 게재 관절성형술을 시행하였다. 그 결과 수술 후 18 개월 째 추시 관찰에서 통증의 경감뿐만 아니라 관절의 안정성도 유지됨을 확인할 수 있었다. 또한 파악력 검사상 우측 $41 \mathrm{~kg}$, 좌측 $39 \mathrm{~kg}$ 으로 거의 정상에 가까운 수부 기능을 회복할 수 있었다.

저자들이 이용한 변형 Dubert 수술법은 비교적 술기가 쉽 고, 제 4,5 중수골 기저부 관절유합술을 시행함으로써 정상적 인 유구골과 제 4 중수골간의 관절을 통해 횡 중수골 궁의 굴 곡-신전 운동이 일어날 수 있도록 할 수 있다. 그러므로 유구 중수 관절유합술 후에 발생할 수 있는 외삼각골과 유구골 관 절의 과부하를 막을 수 있다는 장점이 있다.
제5 수근 중수골 골절 및 탈구 환자에서 조기 치료 및 치료 가 되지 않으면 관절의 주위 구조물과의 관계 등으로 인해 외 상성 관절염을 포함한 여러 가지 합병증이 잘 발생할 수 있음 을 상기하고, 발생한 관절염에 대해서는 제 4,5 중수골 기저 부 관절유합술을 시행하는 것도 하나의 유용한 방법으로 생각 된다.

\section{REFERENCES}

1. Lee SH, Park JW, Kim JI, Lee SJ. Operative treatment in the delayed diagnosed fracture and dislocation of hamatometacarpal joint. J Korean Fract Soc. 2011;24:249-55.

2. Yi CH, Oh JR. Comparison of early fixation and late fusion of 4, 5th carpometacarpal joint in the intra-articular fractures of 4 th and 5 th metacarpal base. J Korean Fract Soc. 2011;24:60-6.

3. Clendenin MB, Smith RJ. Fifth metacarpal/hamate arthrodesis for posttraumatic osteoarthritis. J Hand Surg Am. 1984;9:374-8.

4. Black DM, Watson HK, Vender MI. Arthroplasty of the ulnar carpometacarpal joints. J Hand Surg Am. 1987;12: 1071-4.

5. Gainor BJ, Stark HH, Ashworth CR, Zemel NP, Rickard TA. Tendon arthroplasty of the fifth carpometacarpal joint for treatment of posttraumatic arthritis. J Hand Surg Am. 1991;16:520-4.

6. Proubasta IR, Lamas CG, Ibanez NA, Lluch A. Treatment of little finger carpometacarpal posttraumatic arthritis with a silicone implant. J Hand Surg Am. 2013;38:1960-4.

7. Bain GI, Unni PM, Mehta JA, Eames MH. Arthrodesis of ring finger and little finger metacarpal bases for little finger carpometacarpal joint arthritis. J Hand Surg Br. 2004;29:449-52.

8. Dubert T. Stabilized arthroplasty of the 5th metacarpal bone: a therapeutic proposal for the treatment of old fractures-luxations of the 5th metacarpal bone. Ann Chir Main Memb Super. 1994;13:363-5. 


\section{제5 수근중수 외상성 관절염에 대한 제 4,5 중수골 기저부 관절유합술}

\section{강철형 · 손은석 · 조철현}

계명대학교 의과대학 정형외과학교실

제5 수근중수 외상성 관절염은 관절 내 분쇄 골절 후 또는 정확한 진단이 되지 않아 적절한 치료를 받지 못한 경우에 잘 발생하며 이로 인해 지속적인 동통 및 수부 기능의 저하를 초래하게 된다. 이에 대해 치료로는 관절유합술, 절제 관절성 형술, 삽입 관절성형술 등이 소개되어 있지만 드문 빈도로 인해 그 치료 결과에 대한 보고가 매우 드물다. 저자들은 진 단이 간과된 후에 발생한 제 5 수근중수 외상성 관절염 1 예에 대해 제 4,5 중수골 기저부 관절유합술을 시행한 후 좋은 결과를 경험하였기에 문헌 고찰과 함께 보고하고자 한다.

색인단어: 수근중수 관절, 골절, 관절염, 관절유합술

접수일 2013년 10월 8일 수정일 2013년 11월 2일 게재확정일 2013년 11월 12일 교신저자 조철현 대구광역시 중구 달성로 56 번지 계명대학교 의과대학 정형외과학교실

TEL 053-250-7729 FAX 053-250-7205

E-mail oscho5362@dsmc.or.kr 